\title{
Micro-micromechanical Properties of Weld Metal
}

\author{
Walter L. Costin ${ }^{1}$, A. K. Basak ${ }^{2}$ \\ ${ }^{1}$ School of Mechanical Engineering, The University of Adelaide, South Australia, 5005 \\ ${ }^{2}$ Adelaide Microscopy, The University of Adelaide, Adelaide, South Australia, 5005
}

Hydrogen Assisted Cold Cracking (HACC), also referred to as delayed cracking or cold cracking, is a weld defect which may form in the heat affected zone (HAZ) of the parent metal or the weld metal (WM). Failure usually occurs after the deposited weld has cooled down to temperatures below $200{ }^{\circ} \mathrm{C}$ and can be initiated within minutes to even days after welding [1] and attributed to micro-mechanical properties of the representing microstructures [2,3] in weld zone. Micro-fracture experiments, to determine the properties in specific microstructural regions, were studied in this study. Microscopic cantilever shaped test specimens were fabricated with Focused Ion Beam (FIB) techniques in localized region consisting of predominantly acicular ferrite microstructure followed by loading with nanoindentation for fracture tests.

Three micro-cantilever shaped test specimens with pentagonal cross sections were fabricated in selected region as shown in Fig. 1. The methodology for the preparation was based on the technique developed by Davidson et al [4]. A narrow notch was then milled about $7 \mu \mathrm{m}$ from the support of the beam to create an artificial stress concentrator with defined geometries as shown details in Fig. 2.

The Scanning Electron Microscope (SEM) image (Fig. 3) of the tested specimen shows that the failure process was associated with the development of a plastic hinge with the rotation centre shifted to the beam support. This shift of the rotation center from the notch tip location towards the support may indicate a significant effect of the support on fracture mechanism due to insufficient depth of the notch. Relatively large plastic zone compared to the small sample size implies that linear elastic fracture mechanics (LEFM) is not applicable. However, recent investigations have used methods based on elasto - plastic fracture mechanics (EPFM) to obtain valid fracture toughness values for semi brittle materials [5]. The crack tip opening displacement (CTOD) was used as a parameter to describe the static fracture resistance of the tested material. The measurement of the CTOD was based on an analytical hinge model, which has been adopted for the notched micro-cantilever geometries. The results showed good correlation with the properties measured in macroscopic samples. Although the material tested in this study was not polycrystalline and less ductile, similar methods may be applicable for fracture toughness measurements in selected ferrite morphologies.

References:

[1] Barbaro F. J., 1999, "Types of Hydrogen Cracking in Pipeline Girth Welds," WTIA/APIA/CRC-WS International Conference Weld Metal Hydrogen Cracking in Pipeline Girth Welds Wollongong, NSW, Austalia.

[2] Kuzmikova L., Barbaro F. J., Norrish J. \& Li H., 2012, "Weld Metal Hydrogen Assisted Cold Cracking in High Strength Low Alloy Steels," SEAISI Conference \& Exhibition, Bali, Indonesia.

[3] Wongpanya P., Boellinghaus Th., Lothongkum G. and Hoffmeister H., 2009, "Numerical modelling of cold cracking initiation and propagation in S 1100 QL steel root welds," Welding in the World, 53(3).

[4] Davidson J. L., and Olson D. L. R., 1997, Hydrogen management in steel weldments: joint seminar, Melbourne, Australia, 23rd October 1996: proceedings of the seminar, Published by 
the Organising Committee of the Joint Seminar on behalf of Defence Science and Technology Association and Welding Technology Institute of Australia.

[5] Wurster S., Motz C. and Pippan R., 2012, "Characterization of the fracture toughness of micro-sized tungsten single crystal notched specimens," Philosophical Magazine, 92(14), pp. 1803-1825.

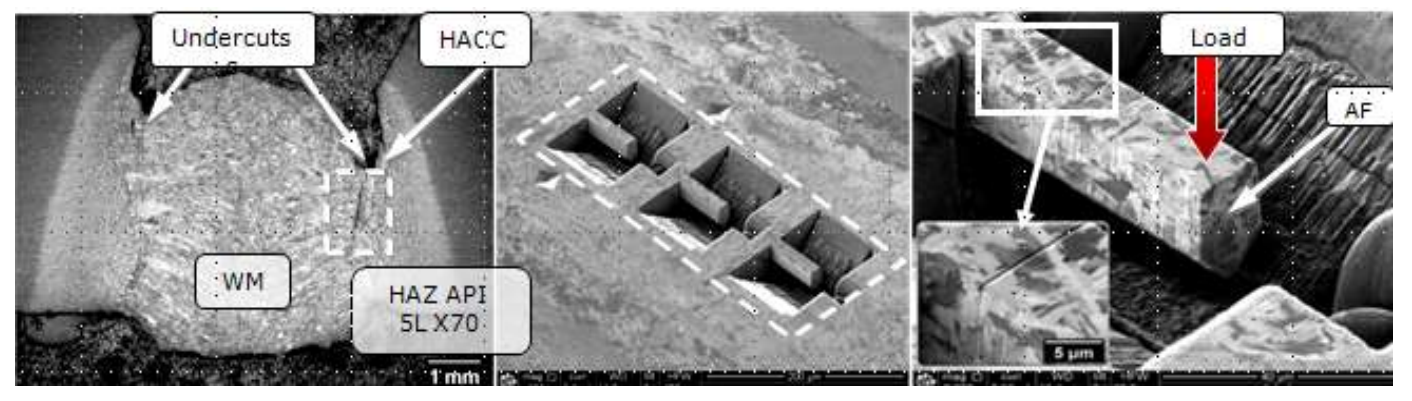

Figure 1. Optical micrograph of selected crack (left) and FIB milled specimens for micro fracture experiments in acicular ferrite region (middle and right).
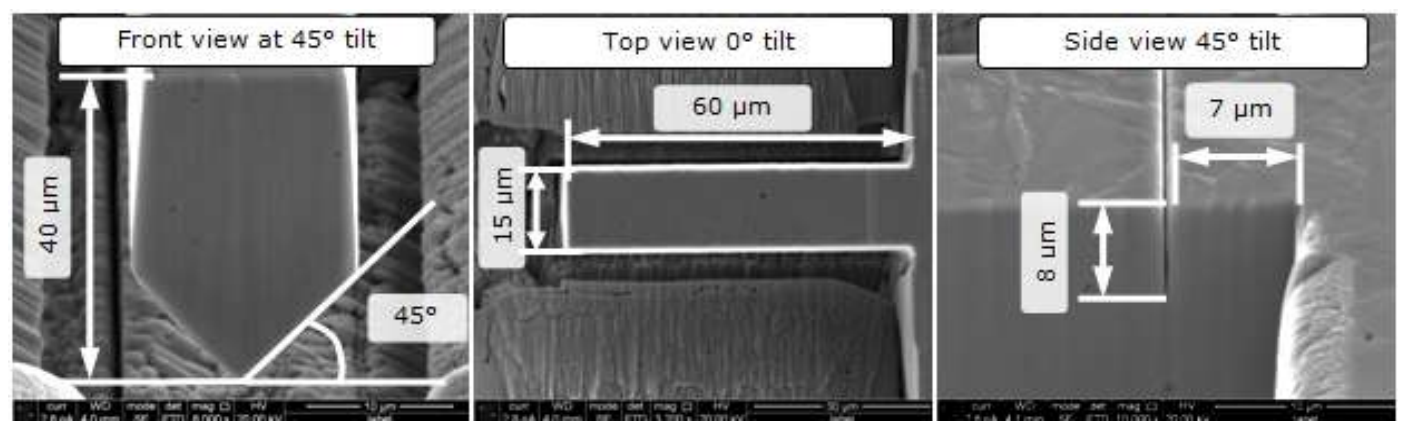

Figure 2. Final specimen dimensions of FIB milled micro-cantilever.

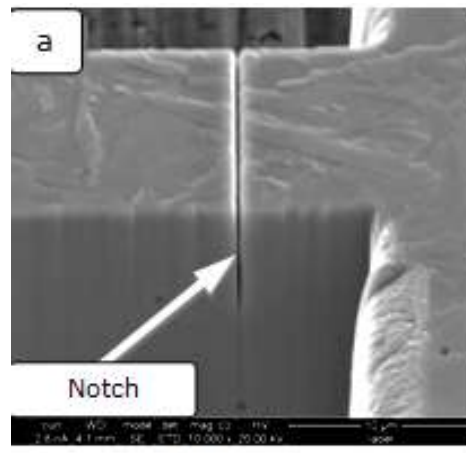

Notch before testing

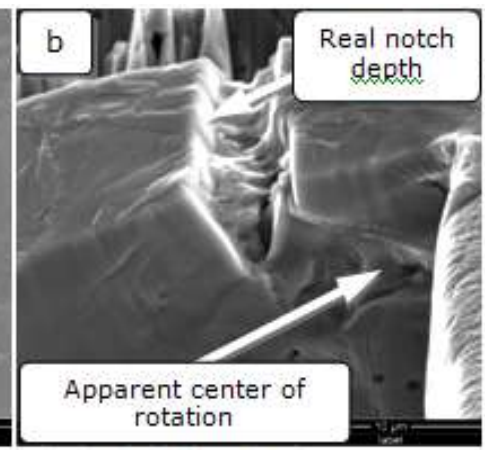

Notch after testing

Figure 3. SEM of the test specimen before and after testing.

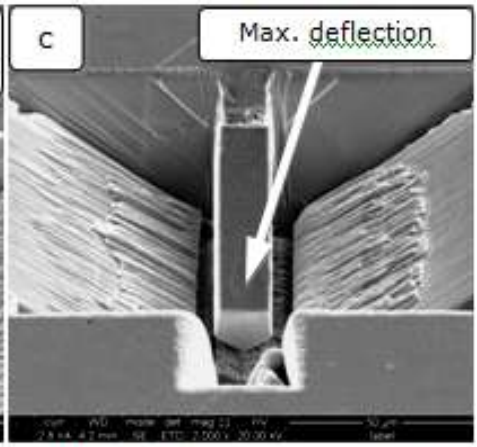

Deflected beam in contact with the bottom of the trench 